\section{(1) \\ CrossMark}

\title{
Management of hypertension in obstructive sleep apnoea: predicting blood pressure reduction under continuous positive airway pressure
}

\author{
Renaud Tamisier ${ }^{1,2}$ and Patrick Lévy $y^{1,2}$ \\ Affiliations: 'Univ. Grenoble Alpes, Inserm, HP2 Laboratory, Grenoble, France. ${ }^{2}$ Sleep Laboratory, Thorax and \\ Vessels Dept, Grenoble Alpes University Hospital, Grenoble, France.
}

Correspondence: P. Lévy, Maison J. Kuntzmann, 110 rue de la chimie, Saint-Martin-d’Hères, 38400, France. E-mail: PLevydachu-grenoble.fr

@ERSpublications

24-hour BP measurement and nocturnal heart rate may help to predict BP response to CPAP. Further studies are needed http://ow.ly/YBBn30fgpWZ

Cite this article as: Tamisier R, Lévy P. Management of hypertension in obstructive sleep apnoea: predicting blood pressure reduction under continuous positive airway pressure. Eur Respir J 2017; 50: 1701822 [https://doi.org/10.1183/13993003.01822-2017].

Hypertension affects a quarter of the adult population and remains a leading cause of cardiovascular mortality, accounting for $13.5 \%$ of all deaths. Half of all strokes and ischaemic heart disease events are attributable to high blood pressure (BP) [1, 2]. Most patients exhibit Grade-I hypertension (systolic BP of 140 to $159 \mathrm{mmHg}$ and/or diastolic $\mathrm{BP}$ of 90 to $99 \mathrm{mmHg}$ ) without co-existing cardiovascular disease. An active reduction of BP results in a significant reduction in stroke and death [3].

Obstructive sleep apnoea (OSA) is now recognised in European and US International Guidelines [4] as a risk factor for the development of hypertension. OSA and hypertension are linked in a dose-response fashion. In OSA patients, elevated BP is essentially explained by intermittent hypoxia inducing increased sympathetic tone and impaired baroreflex gain [5]. Altered arterial vasoconstriction and vasodilation [6] owing to stimulation of the renin angiotensin aldosterone system (RAAS) [7] are also significant contributors [4, 8].

Although OSA and hypertension are tightly linked, the impact of short-term OSA treatment on BP reduction in unselected OSA populations is rather mild (a reduction of about $2 \mathrm{mmHg}$ in 24 -h mean BP). This effect is slightly higher in patients compliant with continuous positive airway pressure (CPAP) or mandibular advancement devices, presumably by allowing rapid eye movement (REM) sleep episodes at the end of the night to be free of respiratory events [9-11]. For instance, it has been evidenced that a reduction in $\mathrm{BP}$ as well as a reduced incidence of hypertension cannot be obtained until a minimum of 4 to $6 \mathrm{~h}$ of CPAP is realised $[12,13]$. BP response to CPAP also appears to be dependent on sleep apnoea severity [14-16] and is very limited in patients who are minimally symptomatic [9]. Whether sleepiness is critical in predicting the CPAP reduction in BP is still under discussion [16-18] but is probably unlikely [19]. In any case, it is clear that BP response to CPAP is highly variable between individuals. Combined treatments associating OSA suppression on the one hand with classical medications for hypertension on the other are expected to be synergistic, as they target complementary pathways originating elevated BP in these patients [20]. Previous studies [21, 22] have demonstrated that, in OSA hypertensive patients,

Received: Sept 052017 | Accepted: Sept 052017

Conflict of interest: None declared.

Copyright OERS 2017 
Losartan or Valsartan are more effective by far than CPAP for reducing BP even if nocturnal BP is better controlled when CPAP is associated with these medications.

There are thus two strategies that can be implemented in OSA patients presenting with untreated hypertension, although these are not mutually exclusive. On the one hand, after a CPAP-trial or any other treatment assessment period, a pharmacological treatment can be implemented in any individual patient targeting BP normalisation, since BP normalisation has not been previously obtained under CPAP alone [20]. On the other hand, individual variability could be related at least in part to epigenetic factors [23]. Thus, identifying clinical and biological phenotypes that best predict the BP response to treatment may be useful. Interest should be focused on night-time BP effects, based on evidence that night-time BP is a BP measure with better predictive value for cardiovascular morbi-mortality [4, 24].

In this issue of the European Respiratory Journal, CASTRO-GRATTONI et al. [25] design a pre-post study to identify clinical characteristics at baseline that could allow the discrimination of patients who would benefit from CPAP treatment from those who would not with regard to BP (including 24-h ambulatory BP monitoring (24-h ABPM), a sleep study and cardiovascular biomarkers). This observational, multicentre study was aimed at assessing changes in BP after a 6-month CPAP treatment period in 88 patients newly diagnosed with severe OSA (apnoea-hypopnoea index $(\mathrm{AHI})=42.5 \cdot \mathrm{h}^{-1}$; range: $29.9-58.9$ ). Patients were middle-aged, obese men with an Epworth Sleepiness Scale (ESS) score of 10.7 \pm 5.02 . Of these, $28.4 \%$ had previously reported hypertension, $34.1 \%$ exhibited a non-dipper circadian pattern and $50 \%$ had nocturnal hypertension. Of the 88 patients, only 60 were included in the post-CPAP analysis and in the multivariate model. After the 6-month CPAP treatment there was a significant reduction in ESS, red blood cells, haemoglobin and norepinephrine urine levels. Despite the marked reduction in the norepinephrine level, no significant changes were found regarding 24-h BP (mean, systolic BP and diastolic BP) or night-time BP. Only daytime BP was significantly reduced after treatment $(-2 \mathrm{mmHg}$; $\mathrm{p}=0.018)$ and compliant patients also experienced a significant reduction $(-2 \mathrm{mmHg})$ in daytime systolic BP $(p=0.047)$, daytime diastolic BP $(p=0.0014)$ and 24-h diastolic BP $(p=0.026)$. After CPAP treatment, nocturnal normotensive patients showed an increase in night-time mean BP (median increase: $+4 \mathrm{mmHg}$; $\mathrm{p}=0.008$ ), night-time systolic BP (median increase: $+5 \mathrm{mmHg} ; \mathrm{p}=0.014$ ) and night-time diastolic BP (median increase: $+3 \mathrm{mmHg} ; \mathrm{p}=0.008$ ). In contrast, patients with nocturnal hypertension showed a decrease in 24-h mean BP (median decrease: $-3 \mathrm{mmHg}$; $=0.011$ ), 24-h systolic BP (median decrease: $-4 \mathrm{mmHg}$; $=0.015$ ) and 24-h diastolic BP (median decrease: $-2 \mathrm{mmHg}$; $=0.017$ ) after CPAP treatment.

A linear, multiple regression model was used to identify the clinical and biological variables at baseline that could predict post-CPAP changes in night-time BP. CPAP compliance was included in the model, as was the interaction between BP dipping status and night-time mean heart rate (HR), and this allowed the definition of four OSA phenotypes. Dipper patients with a low night-time HR, particularly non-compliant patients, exhibited a marked increase in night-time mean BP after CPAP treatment (non-compliers: +9.7 mmHg; $\mathrm{p}=0.0013$ and compliers: $+5.4 \mathrm{mmHg} ; \mathrm{p}=0.0007$ ). In dipper and non-dipper patients with a high night-time HR $(\geqslant 68 \mathrm{bpm})$ the change in BP was neutral after CPAP treatment. Finally, non-dipper patients with a low night-time HR showed a decrease in night-time BP after CPAP treatment (median decrease: $-6.2 \mathrm{mmHg} ; \mathrm{p}<0.01$ ), an important improvement. Patients compliant with CPAP exhibited the greatest night-time BP decrease $(-7.1 \mathrm{mmHg} ; \mathrm{p}=0.0014)$.

There are some limitations in the present paper-the final sample $(n=60)$ is not particularly large for the purposes of establishing predictive factors and there is some heterogeneity in the diagnostic methods. Finally, there is no control group and therefore the natural evolution of BP in untreated OSA is not taken into account. However, the former points are unlikely to affect the main results, while the lack of a control is unlikely to strongly interfere with the present data.

Reduced BP was observed after CPAP in patients with nocturnal hypertension and in non-dipper patients with at least $4 \mathrm{~h}$ of CPAP use per night. However, increased BP was observed in nocturnal normotensive patients and in dipper patients with a low HR, even among CPAP compliant subjects. This is important information which may significantly affect our clinical practice if further confirmed. If we allow that the sample is representative of different OSA phenotypes then it is important to note that other factors than OSA severity and CPAP compliance may be important. It is not unexpected that nocturnal hypertension and non-dipping represent favourable factors for CPAP to be effective in reducing BP. Sympathetic activation is associated with repeated apnoeas and is one of the major factors preventing BP decrease during sleep. Sympathetic activation can be further increased during REM sleep, leading to an additional increase in BP $[4,8]$. Suppressing apnoeas reduces sympathetic activity and can lead to a persistent reduction in $\mathrm{BP}$, including dipping, during $\mathrm{CPAP}$ treatment.

What is less-expected is the increase in night-time mean BP after CPAP treatment that occurs in dipping patients with low night-time HR, particularly the non-compliant subjects. The mean increase of between 5 
and $9.7 \mathrm{mmHg}$ is highly significant and is actually of a comparable magnitude to that which occurs in the best CPAP responders in terms of BP reduction. There are previously published data suggesting CPAP can be detrimental, particularly in minimally symptomatic patients or those with low compliance $[9,26,27]$. The need to identify specific subsets of patients who will more likely benefit from CPAP treatment and those who may be adversely affected is emphasised by CASTRO-GRATTONI et al. [25]. The characterisation of OSA phenotypes and the impact of CPAP treatment on the spectrum of OSA thus constitute a first step in the accurate application of precision medicine [23].

The mechanisms underlying these different responses to CPAP are unclear. The persistence of dipping BP and low HR are described by CASTRO-Grattoni et al. [25] as an adaptation to OSA stress which counterbalances sympathetic hyperactivity. One may imagine that adding another sympathetic activation (e.g. changes in pressure and arousals associated with CPAP) could lead to increases instead of decreases in BP. It would also be of interest to determine in further studies whether CPAP settings can make a difference, as evidenced between automatic positive airway pressure (APAP) and CPAP [28]. Finally, although further studies are needed to confirm these findings, this is a strong call for the precise phenotyping of OSA patients, particularly using 24-h ABPM [24] and nocturnal HR measurement.

\section{References}

1 Kearney PM, Whelton M, Reynolds K, et al. Global burden of hypertension: analysis of worldwide data. Lancet 2005; 365: 217-223.

2 Lawes CM, Vander Hoorn S, Rodgers A. Global burden of blood-pressure-related disease, 2001. Lancet 2008; 371: 1513-1518.

3 Sundstrom J, Arima H, Jackson R, et al. Effects of blood pressure reduction in mild hypertension: a systematic review and meta-analysis. Ann Intern Med 2015; 162: 184-191.

4 Parati G, Lombardi C, Hedner J, et al. Recommendations for the management of patients with obstructive sleep apnoea and hypertension. Eur Respir J 2013; 41: 523-538.

5 Tamisier R, Pépin JL, Rémy J, et al. 14 nights of intermittent hypoxia elevate daytime blood pressure and sympathetic activity in healthy humans. Eur Respir J 2011; 37: 119-128.

6 Grote L, Kraiczi H, Hedner J. Reduced $\alpha$ - and $\beta_{2}$-adrenergic vascular response in patients with obstructive sleep apnea. Am J Respir Crit Care Med 2000; 162: 1480-1487.

7 Lacedonia D, Tamisier R, Roche F, et al. Respective effects of OSA treatment and angiotensin receptor blocker on aldosterone in hypertensive OSA patients: a randomized cross-over controlled trial. Int J Cardiol 2014; 177: 629-631.

8 Lévy P, Kohler M, McNicholas WT, et al. Obstructive sleep apnoea syndrome. Nat Rev Dis Primers 2015; 1: 15015.

9 Bratton DJ, Stradling JR, Barbé F, et al. Effect of CPAP on blood pressure in patients with minimally symptomatic obstructive sleep apnoea: a meta-analysis using individual patient data from four randomised controlled trials. Thorax 2014; 69: 1128-1135.

10 Mokhlesi B, Hagen EW, Finn LA, et al. Obstructive sleep apnoea during REM sleep and incident non-dipping of nocturnal blood pressure: a longitudinal analysis of the Wisconsin Sleep Cohort. Thorax 2015; 70: 1062-1069.

11 Bratton DJ, Gaisl T, Wons AM, et al. CPAP vs mandibular advancement devices and blood pressure in patients with obstructive sleep apnea: a systematic review and meta-analysis. JAMA 2015; 314: 2280-2293.

12 Barbe F, Duran-Cantolla J, Carmona C, et al. Effect of CPAP treatment on the incidence of cardiovascular events and hypertension in non-sleepy OSAS patients. A long-term RCT. Am J Respir Crit Care Med 2010; 181: A5559.

13 Marin JM, Agusti A, Villar I, et al. Association between treated and untreated obstructive sleep apnea and risk of hypertension. JAMA 2012; 307: 2169-2176.

14 Pepperell JC, Ramdassingh-Dow S, Crosthwaite N, et al. Ambulatory blood pressure after therapeutic and subtherapeutic nasal continuous positive airway pressure for obstructive sleep apnoea: a randomised parallel trial. Lancet 2002; 359: 204-210.

15 Becker HF, Jerrentrup A, Ploch T, et al. Effect of nasal continuous positive airway pressure treatment on blood pressure in patients with obstructive sleep apnea. Circulation 2003; 107: 68-73.

16 Haentjens P, Van Meerhaeghe A, Moscariello A, et al. The impact of continuous positive airway pressure on blood pressure in patients with obstructive sleep apnea syndrome: evidence from a meta-analysis of placebo-controlled randomized trials. Arch Intern Med 2007; 167: 757-764.

17 Barbé F, Mayoralas LR, Duran J, et al. Treatment with continuous positive airway pressure is not effective in patients with sleep apnea but no daytime sleepiness: a randomized, controlled trial. Ann Intern Med 2001; 134: $1015-1023$.

18 Robinson GV, Smith DM, Langford BA, et al. Continuous positive airway pressure does not reduce blood pressure in nonsleepy hypertensive OSA patients. Eur Respir J 2006; 27: 1229-1235.

19 Barbé F, Durán-Cantolla J, Capote F, et al. Long-term effect of continuous positive airway pressure in hypertensive patients with sleep apnea. Am J Respir Crit Care Med 2010; 181: 718-726.

20 Tamisier R, Lévy P, Pépin JL. Do patients with obstructive sleep apnoea deserve new dedicated antihypertensive strategies? Thorax 2017; 72: 495-497.

21 Pepin JL, Tamisier R, Barone-Rochette G, et al. Comparison of continuous positive airway pressure and valsartan in hypertensive patients with sleep apnea. Am J Respir Crit Care Med 2010; 182: 954-960.

22 Thunström E, Manhem K, Rosengren A, et al. Blood pressure response to losartan and continuous positive airway pressure in hypertension and obstructive sleep apnea. Am J Respir Crit Care Med 2016; 193: 310-320.

23 Sánchez-de-la-Torre M, Khalyfa A, Sánchez-de-la-Torre A, et al. Precision medicine in patients with resistant hypertension and obstructive sleep apnea: blood pressure response to continuous positive airway pressure treatment. J Am Coll Cardiol 2015; 66: 1023-1032. 
24 Baguet JP, Hammer L, Lévy P, et al. Night-time and diastolic hypertension are common and underestimated conditions in newly diagnosed apnoeic patients. J Hypertens 2005; 23: 521-527.

25 Castro-Grattoni AL, Torres G, Martínez-Alonso M, et al. Blood pressure response to CPAP treatment in subjects with obstructive sleep apnoea: the predictive value of 24 -h ambulatory blood pressure monitoring. Eur Respir J 2017; 50: 1700651.

26 Barbé F, Durán-Cantolla J, Sánchez-de-la-Torre M, et al. Effect of continuous positive airway pressure on the incidence of hypertension and cardiovascular events in nonsleepy patients with obstructive sleep apnea: a randomized controlled trial. JAMA 2012; 307: 2161-2168.

27 Martínez-García MA, Capote F, Campos-Rodríguez F, et al. Effect of CPAP on blood pressure in patients with obstructive sleep apnea and resistant hypertension: the HIPARCO randomized clinical trial. JAMA 2013; 310: 2407-2415.

28 Pépin JL, Tamisier R, Baguet JP, et al. Fixed-pressure CPAP versus auto-adjusting CPAP: comparison of efficacy on blood pressure in obstructive sleep apnoea, a randomised clinical trial. Thorax 2016; 71: 726-733. 